\title{
Relation between Nurse-Nurse Collaboration And Missed Nursing Care Among Intensive Care Nurses
}

\author{
Farida Mahmoud Hussein Hassona ${ }^{1}$, Marwa Abd El-Aziz ${ }^{2}$ \\ ${ }^{1}$ (Nursing Administration Department, Faculty of Nursing / Zagazig University, Egypt \\ ${ }^{2}$ (Medical and surgical Department, Faculty of Nursing/ Helwan University, Egypt
}

\begin{abstract}
Effective collaboration among nurses and within organizations has been reported as an essential element to provide safe and effective therapeutic environment for patients. Therefore, the aim of this study was to explore the relation between nurse-nurse collaboration and missed nursing care among intensive care nurses. Descriptive correlational study design was used. Three tools were used to collect data; demographic data sheet, Nurse-Nurse Collaboration scale, and Missed Nursing Care Questionnaire. 216 nurse were selected randomly from ICUs of Zagazig University hospital and Ain Shams University Specialized Hospital, Egypt. The results revealed that the highest percentage of the studied nurses had satisfactory level in all nurse-nurse collaboration subscales, 70.4\% of the studied nurses most frequently missed nursing care related to patient assessment. While, $63.9 \%$ most frequently missed nursing care related to medication administration. The significant reasons of missed nursing care as reported by nurses were inadequate nursing, number and condition of patient, and unavailability of medications when needed. Statistical significant negative correlation between all nurse-nurse collaboration subscales and missed nursing care was detected. The study recommended that hospital managers and nurse educators should develop educational programs that focus on creating innovative opportunities for nurses to learn about intra-professional collaboration in the practice setting.
\end{abstract}

Keywords: Nurse-Nurse collaboration, missed nursing care, intensive care unit

\section{Introduction}

Nowadays, great emphasize was directed toward improving collaboration among health care professionals in an attempt to improve quality of patient care as well as decreasing medical errors [1] . Collaborative practice has been found to be of great importance especially among Intensive Care nurses, because intensive care unit (ICU) work is complex and intense so, nurses should be prepared to deliver care to patients with important homodynamic alterations at any time, which demand specific knowledge, great skills to make decisions, and the interactions of various health care providers [2,3]. Therefore, Intensive care nurses should be able to use a comprehensive approach in which experience should be combined with technical and scientific knowledge [4, 5].

Effective collaboration among nurses and within organizations is essential in order to provide safe, competent nursing practice, and to achieve quality patient outcomes. Nurses are expected to collaborate with patients, with each other and with members of the health care team not only for the benefit of patients but also for the satisfaction of health care providers [6]. Moreover, its recommended to reduce medication errors and improve patient care which in turn increase in patient safety. Accordingly, increasing collaboration among nurses is critical in maintaining a safe and effective therapeutic environment for patients [7].

When nurses and groups collaborate or work together successfully, this will promote active participation regarding patient care, share perspectives, plan together, respect one another, and support and assist each other in the interest of patient care [6]. Hence, collaboration is a key strategy for improvement, problem solving, and innovation in the health system [8]. Collaboration is defined as an interpersonal relationship between and among colleagues which require a high level of communication, coordination, conflict management strategies, shared process and professionalism [7].

Collaboration is a type of teamwork in which a group of people working together to achieve a common or one goal. But differ than team work in that, individuals in the group work together and feeling off one another, making decisions together, and working jointly rather than separately to achieve their own goal [9]. However, nursing collaboration is a complex and multifaceted process that faces many barriers such as poor communication, lack of team work, role conflict, lack of problem solving skills, and inconsistencies which prevent nurses from working together effectively causing medication related problems to their patients and missed nursing care [10].

Missed nursing care is much prevalent and detrimental and can lead to serious adverse patient outcomes which in turn affect quality of care. So, missed nursing care must be measured and acknowledged in nursing research [11]. Missed nursing care was defined as "any aspect of required patient care that is omitted 
(either in part or in whole) or delayed" [12] (p. 1510). Previous studies were conducted to assess medication errors, one study was conducted by Khalifa and colleagues [13] at Zagazig University Hospitals, the other study was conducted by Sabry and colleagues [14] in Egyptian Teaching Hospitals, both studies concluded that there were high rate of medication errors . Although those studies indicated that there were a high rate of medication errors, no studies were done to examine if nurse-nurse collaboration relate to missed nursing care or not.

Moreover, Attia [15] conducted a study to examine the impact of nursing teamwork on missed nursing care in intensive care units at Zagazig University Hospitals. The findings revealed a negative correlation between the total scores of nursing teamwork and the total scores of missed nursing care. Although that study reported the relationship between teamwork and missed nursing care. The different nature between collaboration concept and teamwork creates an urgent need to describe the relation between nurse-nurse collaboration and missed nursing care.

1.1. Significance of the study: Effective collaboration among nurses and within organizations has been reported as an essential element to provide safe and effective therapeutic environment for patients. Moreover, previous studies have shown that missed nursing care is a significant problem in acute care hospitals that threats patient safety. However, limited studies were conducted to explore the relationship between nurse-nurse collaboration and missed nursing care, despite the fact that nurses are the principle care providers in the hospital setting. They considered the largest number of personnel working in any hospital.

1.2. Aim of the study: The aim of this study was to explore the relation between nurse-nurse collaboration and missed nursing care among intensive care nurses

\subsection{Research questions}

1.3.1 What is the level of nurse-nurse collaboration among intensive care nurses?

1.3.2 What are the most frequently missed types of nursing care from nurses' opinion?

1.3.3 What are the reasons of missed nursing care from nurses' opinion?

1.3.4 Is there a relationship between nurse-nurse collaboration subscales and missed nursing care?

\section{Subjects and methods}

2.1 Research design: Descriptive correlational study design was used.

2.2 Setting: The present study was conducted in intensive care units of two university hospitals; Zagazig university hospitals and Ain Shams University Specialized Hospital.

2.3 Sample: Simple random sample was used. Sample size was calculated using a simplified formula $\left(\mathrm{n}=\mathrm{N} / 1+\mathrm{N}(\mathrm{e})^{2}\right.$ which provided by Yamane [16] to be 216 nurses. A 95\% confidence level and $\mathrm{P}=0.05$ are assumed for Equation. Where ' $\mathrm{n}$ ' is sample size. ' $\mathrm{N}$ ' is Number of population $=471$ (total number of ICU nurses in both hospitals). 'e' is Coefficient factor $=0.05$. Then, the required number of nurses from each hospital was calculated with the following formula (number of nurses in each hospital $\times$ required sample size / total number of nurses in all hospitals). Nurses were randomly assigned to fulfill the required sample size from both hospitals. Accordingly 216 nurses were chosen as follow; 121 nurses from Zagazig University Hospitals and 95 nurses from Specific Ain Shams Hospital.

2.4 Inclusion criteria: The inclusion criteria for this study sample include: intensive care nurses who agreed to participate in the study with an overall responsibility for provision of direct nursing care to patients and having at least one year of experience (new nurses may need time to be familiar with the hospital structure and its policy).

2.5 Tools of data collection: Three tools were used for data collection.

2.5.1 Tool I:Demographic data. It was developed by the researcher to collect data about age, gender, qualification, and years of experience of the studied nurses.

2.5.2 Tool II: Nurse-nurse collaboration scale (NNC): it was developed by Dougherty and Larson [7]. It includes five sub scales of collaboration: conflict management ( 7 items), communication ( 8 items), shared process ( 8 items), coordination (5 items), and professionalism ( 7 items). Items are scored as follows: strongly disagree (1), disagree (2), agree (3), and strongly agree (4). The exceptions to this scoring rubric are items $1.5,1.6,1.7,2.5,2.6,2.7$, and 2.8 , which are reverse scored: (4) strongly disagree, (3) disagree, (2) agree, and (1) strongly agree. For nurse-nurse collaboration subscales, the subscale was considered to be satisfactory if the percent score was $60 \%$ or more, and unsatisfactory if less than $60 \%$. Cronbach's alpha for the overall scale as reported by the developed author was 0.89 . The instrument did not measure a global concept but rather 5 separate domains of collaboration. Internal consistency testing of the 5 subscales produced acceptable results ranging from .66 to .91. In this study Cronbach's alpha for the overall scale was 0.877. Cronbach's alpha for the 5 subscales was 0.698 for conflict management, 0.738 for communication subscale, 0.786 for shared processes subscale, 0.773 for coordination subscale, and 0.841 for professionalism. Indicating high reliability of the tool. 


\subsubsection{Tool III: Missed Nursing Care Questionnaire. It was developed by Kalisch and William [17]. It} consists of two parts

2.5.3.a. used to identify how frequently the elements of nursing care are missed from nurses' opinion. It includes 24 items with response to five point Likert scale ranged from 1 (never missed) to 5 (always missed) grouped under 9 domains as follows: Patient assessment (6 items); Medication administration (4items); Patient education (3 items); Feeding ( 2 items); Hygiene ( 3 items); Mobilization ( 2 items); Response to patient need ( 2 items); Attendance interdisciplinary conference $(1 \mathrm{item})$; Documentation of all necessary data for patient $(1 \mathrm{item})$. The total score of the missed nursing care scale was categorized into never missed: $1-48$, slightly missed: $49-72$, and most frequently missed: $73-120$. Internal consistency was measured by Cronbach's alpha. The alpha coefficient for the overall 24 items of missed nursing care elements ranged from 0.76 to 0.93 [18]. In this study the alpha coefficient for the overall 24 items of missed nursing care was 0.875

2.5.3.b. It was used to assess the opinion of nurses regarding the reasons of missed nursing care. It includes 17 items with four point Likert scale ranged from 4 (significant reason) to 1 (not a reason for missed nursing care) grouped under 7 domains as follows: Communication problems (4 items); Inadequate nursing staff (4 items); support staff (3 items); Numbers and condition of patients (2 items); Material resources (2 items); Heavy admission and discharge activity (1 item); Unavailability of medication when needed (1 item). Internal consistency was measured by Cronbach alpha. The alpha coefficient for the overall 17 items of reasons of missed nursing care ranged from 0.79 to 0.96 . Reliability of the test was high [17].

2.6 Field work: Data was collected using a self-administered questionnaire, after the translation of the instruments to Arabic. Back translation was conducted for all the instruments in this study.

2.6.1 Validity of the tool: The content validity of the instruments after the translation to Arabic was conducted by a group of expertise (3) from academic nursing staff, Cairo University.

2.6.2 Pilot study: A pilot study was done on 22 staff nurses from different ICUs selected randomly (10\% of the study sample) to check for the clarity and feasibility of the tool and to identify the time needed to accomplish the questionnaire by each participant. No modification was done. Results of the pilot sample were excluded from the results.

2.6.3 Data Collection: The questionnaire was distributed on nurses with the help of the head nurses of the selected ICUs after explaining the aim of the study. The answered sheets were collected in a large folder from the participants at their units by hand in the morning, afternoon, and night shifts. The time consumed in answering the questionnaire sheet was about 20 to 25 minutes. It was taken two months to complete data collection (from the 1st of June to the end of July, 2016).

2.7 Administrative and ethical considerations: approval to conduct the study was obtained from the Scientific Research Ethics Committee at faculty of nursing - Zagazig University as well as medical and nursing directors of the hospitals and the head nurses of the units after explaining the aim of the study. The participants were informed that their participation in the study is completely voluntary and there is no harm if they choose not to participate in the study. The anonymity and confidentiality of the data was assured. Written consent was taken from the participants.

2.8 Statistical design: Statistical analysis was done using IBM SPSS 22 statistical software package. Cleaning of data was done to be sure that there is no missing or abnormal data by running frequencies and descriptive statistics. Data was presented using descriptive statistics in the form of frequencies and percentages for categorical variables, means and standard deviations for continuous variables (e.g., age), Pearson correlation analysis was used for assessment of the inter-relationships among quantitative variables. The significant level of all statistical analysis was at $<0.05$ (P-value).

\section{Results}

Table (1): Frequency distribution of demographic characteristics of the studied nurses $(n=216)$

\begin{tabular}{|c|c|c|}
\hline 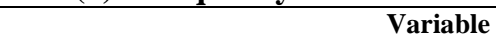 & $\mathrm{N}$ & $\%$ \\
\hline \multicolumn{3}{|l|}{ Age } \\
\hline$<25$ & 66 & 30.56 \\
\hline $25-45$ & 112 & 51.85 \\
\hline$>45$ & 38 & 17.59 \\
\hline Mean \pm SD & \multicolumn{2}{|c|}{$34.699 \pm 10.889$} \\
\hline \multicolumn{3}{|l|}{ Gender } \\
\hline Male & 17 & 7.87 \\
\hline Female & 199 & 92.13 \\
\hline \multicolumn{3}{|l|}{ Education } \\
\hline Nursing Diploma & 120 & 55.56 \\
\hline Nursing Institute technician & 53 & 24.54 \\
\hline
\end{tabular}


Nurse-Nurse Collaboration And Missed Nursing Care Among Intensive Care Nurses

\begin{tabular}{|l|r|r|}
\hline Bachelor of Nursing & 43 & \multicolumn{2}{|c|}{19.91} \\
\hline Years of experience & 47 & 21.76 \\
\hline$<5$ & 64 & 29.63 \\
\hline $5-10$. & 105 & 48.61 \\
\hline$>10$ & \multicolumn{2}{|c|}{$8.842 \pm 3.9829$} \\
\hline
\end{tabular}

Table (1) Shows that $51.85 \%$ of the studied nurses their age was between 25 to 45 years with mean age of $34.70,92.13 \%$ were female, and $55.56 \%$ of the studied nurses had nursing diploma. only $48.61 \%$ had more than 10 years of experience.

Table (2). Percentage distribution of nurse-nurse collaboration subscales among the studied nurses

$(\mathbf{n}=\mathbf{2 1 6})$

\begin{tabular}{|c|c|c|c|c|c|}
\hline \multirow[t]{3}{*}{ Variable } & \multicolumn{4}{|c|}{ Nurse-Nurse collaboration } & \multirow[t]{3}{*}{ Mean \pm SD } \\
\hline & \multicolumn{2}{|c|}{ Unsatisfactory } & \multicolumn{2}{|c|}{ Satisfactory } & \\
\hline & No & $\%$ & No & $\%$ & \\
\hline Conflict management & 25 & 11.6 & 191 & 88.4 & $19.82 \pm 3.23$ \\
\hline Communication & 18 & 8.3 & 198 & 91.7 & $23.82 \pm 3.36$ \\
\hline Shared processes & 35 & 16.2 & 181 & 83.8 & $23.66 \pm 4.34$ \\
\hline Coordination & 27 & 12.5 & 189 & 87.5 & $14.62 \pm 2.90$ \\
\hline Professionalism & 18 & 8.3 & 198 & 91.7 & $21.94 \pm 3.75$ \\
\hline
\end{tabular}

Table (2) shows that $91.7 \%$ of the studied nurses have satisfactory level in communication as well as professionalism subscales, followed by conflict management and coordination subscales $(88.4 \% \& 87.5 \%$ respectively).While, shared processes subscale obtained satisfactory level by $83.8 \%$ only.

Table (3). Percentage distribution of nurses' opinion regarding the most frequently missed nursing care $(n=216)$

\begin{tabular}{|c|c|c|c|c|c|c|c|}
\hline \multirow{3}{*}{ Variable } & \multicolumn{6}{|c|}{ Missed Nursing Care } & \multirow[t]{3}{*}{ Mean \pm SD } \\
\hline & \multicolumn{2}{|c|}{ Never missed } & \multicolumn{2}{|c|}{ Slightly missed } & \multicolumn{2}{|c|}{$\begin{array}{l}\text { Most frequently } \\
\text { missed }\end{array}$} & \\
\hline & No & $\%$ & No & $\%$ & No & $\%$ & \\
\hline Patient assessment & 24 & 11.1 & 40 & 18.5 & 152 & 70.4 & $21.51 \pm 8.52$ \\
\hline Medication administration & 7 & 3.2 & 71 & 32.9 & 138 & 63.9 & $13.49 \pm 4.58$ \\
\hline Patient education & 20 & 9.3 & 73 & 33.8 & 123 & 56.9 & $9.67 \pm 3.76$ \\
\hline Feeding & 19 & 8.8 & 67 & 31.0 & 130 & 60.2 & $6.83 \pm 2.40$ \\
\hline Hygiene & 30 & 13.9 & 77 & 35.6 & 109 & 50.5 & $9.52 \pm 4.31$ \\
\hline Mobilization & 12 & 5.6 & 81 & 37.5 & 123 & 57.0 & $6.70 \pm 2.29$ \\
\hline Response to patient need & 32 & 14.8 & 67 & 31.0 & 117 & 54.2 & $6.60 \pm 2.71$ \\
\hline $\begin{array}{l}\text { Attendance interdisciplinary } \\
\text { conference }\end{array}$ & 33 & 15.3 & 75 & 34.7 & 108 & 50.0 & $3.44 \pm 1.48$ \\
\hline $\begin{array}{l}\text { Documentation of all necessary data } \\
\text { for patient }\end{array}$ & 38 & 17.6 & 74 & 34.3 & 104 & 48.1 & $3.18 \pm 1.44$ \\
\hline Total missed care & 60 & 27.7 & 66 & 30.6 & 150 & 69.4 & $80.97 \pm 26.56$ \\
\hline
\end{tabular}

Table (3) showed that the highest percentage of the studied nurses most frequently missed nursing care related to patient assessment, medication administration, and feeding (70.4\%, 63.9\%, $60.2 \%$ respectively). While, $48.1 \%$ most frequently missed documentation of all necessary data for patient. Overall $69.4 \%$ of the studied nurses most frequently missed nursing care.

Table (4). Percentage distribution of nurses' opinion regarding reasons of missed nursing care $(n=216)$

\begin{tabular}{|c|c|c|c|c|c|c|c|c|c|}
\hline \multirow[t]{3}{*}{ Variable } & \multicolumn{8}{|c|}{ Reasons Of Missed Nursing Care } & \multirow[t]{3}{*}{ Mean \pm SD } \\
\hline & \multicolumn{2}{|c|}{ No reason } & \multicolumn{2}{|c|}{$\begin{array}{l}\text { Mild } \\
\text { reason }\end{array}$} & \multicolumn{2}{|c|}{$\begin{array}{l}\text { Moderate } \\
\text { reason }\end{array}$} & \multicolumn{2}{|c|}{$\begin{array}{c}\text { Significant } \\
\text { reason }\end{array}$} & \\
\hline & No & $\%$ & No & $\%$ & No & $\%$ & No & $\%$ & \\
\hline Communication problems & 5 & 2.3 & 37 & 17.1 & 63 & 29.2 & 111 & 51.4 & $12.28 \pm 3.51$ \\
\hline $\begin{array}{l}\text { Un availability of medications } \\
\text { when needed }\end{array}$ & 7 & 3.2 & 20 & 9.3 & 51 & 23.6 & 138 & 63.9 & $3.48 \pm .79$ \\
\hline Inadequate nursing & 4 & 1.9 & 13 & 6.0 & 46 & 21.3 & 153 & 70.8 & $13.62 \pm 2.92$ \\
\hline $\begin{array}{l}\text { Equipment and material } \\
\text { resources }\end{array}$ & 4 & 1.9 & 20 & 9.3 & 56 & 25.9 & 136 & 63.0 & $6.71 \pm 1.50$ \\
\hline Support staff & 3 & 1.4 & 12 & 5.6 & 80 & 37.0 & 121 & 56.0 & $9.71 \pm 2.17$ \\
\hline $\begin{array}{l}\text { Number and condition of } \\
\text { patient. }\end{array}$ & 7 & 3.2 & 14 & 6.5 & 46 & 21.3 & 149 & 69.0 & $6.88 \pm 1.60$ \\
\hline Heavy admission and discharge & 8 & 3.7 & 54 & 25.0 & 124 & 57.4 & 30 & 13.9 & $2.81 \pm .71$ \\
\hline
\end{tabular}


Table (4) clears that the significant reasons of missed nursing care reported by studied nurses were related to inadequate nursing, number and condition of patient, and unavailability of medications when needed $(70.8 \%, 69 \%, \& 63.9 \%$ respectively). While, $57.4 \%$ of the studied nurses were rated heavy admission and discharge as a moderate reason.

Table (5) correlation between nurse-nurse-collaboration subscales and total missed nursing care among the studied nurses $(n=216)$

\begin{tabular}{|c|c|c|}
\hline Nurse-Nurse collaboration & \multicolumn{2}{|c|}{ Total missed nursing care } \\
\cline { 2 - 3 } Subscales & r- test & p-value \\
\hline Conflict management & -.229 & $.001^{* *}$ \\
\hline Communication & -.302 & $.000^{* *}$ \\
\hline Shared process & -.373 & $.000^{* *}$ \\
\hline Coordination & -.162 & $.017^{*}$ \\
\hline Professionalism & -.241 & $.000^{* *}$ \\
\hline
\end{tabular}

(*) Statistically significant at $\mathrm{p}<0.05$

(**) Statistically significant at $\mathrm{p}<0.01$

Table (5) shows statistical significant negative correlation between total score of missed nursing care and all subscales of nurse-nurse collaboration among the studied nurses ( $\mathrm{p}$ value $<0.05$ ).

Table (6). Correlation between demographic characteristics of the studied nurses, nurse-nurse collaboration subscales, and the total missed nursing missed nursing care $(n=216)$

\begin{tabular}{|c|c|c|c|c|c|c|}
\hline \multirow[t]{2}{*}{ variable } & $\begin{array}{c}\text { Conflict } \\
\text { management }\end{array}$ & Communication & $\begin{array}{l}\text { Shared } \\
\text { process }\end{array}$ & Coordination & Professionalism & $\begin{array}{l}\text { Total Missed } \\
\text { nursing care }\end{array}$ \\
\hline & $\begin{array}{c}\text { r-test } \\
\text { p-value }\end{array}$ & $\begin{array}{c}\text { r-test } \\
\text { p-value }\end{array}$ & $\begin{array}{c}\text { r-test } \\
\text { p-value }\end{array}$ & $\begin{array}{c}\text { r-test } \\
\text { p-value }\end{array}$ & $\begin{array}{c}\text { r-test } \\
\text { p-value }\end{array}$ & $\begin{array}{c}\text { r-test } \\
\text { p-value }\end{array}$ \\
\hline Age & $\begin{array}{c}0.202 \\
0.003^{* *}\end{array}$ & $\begin{array}{l}0.142 \\
0.037^{*}\end{array}$ & $\begin{array}{l}0.060 \\
0.377\end{array}$ & $\begin{array}{l}0.109 \\
0.111\end{array}$ & $\begin{array}{l}0.066 \\
0.333\end{array}$ & $\begin{array}{l}-0.098 \\
0.150\end{array}$ \\
\hline Gender & $\begin{array}{l}0.038 \\
0.581\end{array}$ & $\begin{array}{l}0.093 \\
0.175\end{array}$ & $\begin{array}{c}-0.078 \\
0.251\end{array}$ & $\begin{array}{c}-0.020 \\
0.770\end{array}$ & $\begin{array}{l}-0.027 \\
0.690 \\
\end{array}$ & $\begin{array}{l}0.137 \\
0.045^{*}\end{array}$ \\
\hline $\begin{array}{l}\text { Educational } \\
\text { qualification }\end{array}$ & $\begin{array}{l}-0.176 \\
0.010^{*}\end{array}$ & $\begin{array}{l}0.007 \\
0.923 \\
\end{array}$ & $\begin{array}{l}0.101 \\
0.138 \\
\end{array}$ & $\begin{array}{l}0.016 \\
0.811 \\
\end{array}$ & $\begin{array}{c}-0.068 \\
0.323 \\
\end{array}$ & $\begin{array}{l}0.028 \\
0.688 \\
\end{array}$ \\
\hline $\begin{array}{c}\text { Year of } \\
\text { experience }\end{array}$ & $\begin{array}{l}0.132 \\
0.053\end{array}$ & $\begin{array}{r}-0.004 \\
.958\end{array}$ & $\begin{array}{l}0.110 \\
0.108\end{array}$ & $\begin{array}{l}0.044 \\
0.523\end{array}$ & $\begin{array}{c}0.162 \\
0.017^{*}\end{array}$ & $\begin{array}{l}-0.062 \\
0.365\end{array}$ \\
\hline
\end{tabular}

(*) Statistically significant at $\mathrm{p}<0.05$

(**) Statistically significant at $\mathrm{p}<0.01$

Table (6) shows that there was significant correlation between total missed nursing care and the demographic characteristics of the studied nurses related to gender ( $\mathrm{p}$ value $=.045, \mathrm{r}=.137$ ). The table also shows that conflict management subscale has statistical significant negative correlation with the educational qualification of the studied nurses $(\mathrm{p}$ value $=.010, \mathrm{r}=-.176$ ). However, professionalism subscale has significant positive correlation with the year of experience ( $\mathrm{p}$ value $=0.017, \mathrm{r}=.162$ ). Both of conflict management and communication subscales have significant positive correlation with the age of the studied nurses ( $\mathrm{p}$ value $=$ $0.003, \mathrm{r}=.202 \& \mathrm{p}$ value $=0.037, \mathrm{r}=.142$ respectively).

\section{Discussion}

Collaboration has been identified as an essential element in ensuring appropriate care and treatment especially for the critically ill patient as it enables input from the multidisciplinary team members in promoting decision-making based on more useful information. The current study findings shows that almost all of the study participants were females. This may be due to the enrollment of male to the nursing profession in Egypt is new. Also, male nurses prefer to travel abroad or to work in private hospitals to get more money. This finding coincide with Abd Elrehem et al. [19] who conducted a study to examine "Correlates of Missed Nursing Care in Selected Medical Intensive Care Units, Egypt" and found that (77\%) of the study sample were females and the rest were males.

The findings of the present study also shows that the highest percentage of the studied nurses have satisfactory level in all nurse-nurse collaboration subscales. This may be due to that the nature of the intensive care unit that require great collaboration and various interactions between all health care providers to provide safe and effective care. This finding accord with Metwally and Hassona [20] who conducted a study to describe Collective Self-Esteem, Attitudes Toward Collaboration, and Collaborative Practice Behaviors utilized by Nurses and Physicians at Zagazig university hospital and found that nurse-to-nurse collaboration was high, and go in same line with Tuija et al. [21] who conducted a study to assess "Nurse-Nurse Collaboration - a survey to the registered nurses in a university hospital" and found that nurses working in the hospital were reviewing their collaboration as good (97\%). While, this finding disagree with Serrano-Gemes and Rich-Ruiz [22] who 
conducted a study to measure the intensity of inter-professional collaboration (IPC) in nurses of an intensive care unit (ICU) at a tertiary hospital, the findings of that study reported an average levels of inter-professional collaboration among the study participants.

The findings of the current study also reveals that communication and professionalism subscales have the highest percentage scores compared with other nurse-nurse collaboration subscales. This may be due to that the majority of nurses in this study agreed that it was easy for them to ask advice from nurses in their units, find it enjoyable to talk with other nurses in their unit, there is respectful and cordial relationship among nurses, nurses have adequate knowledge about disease process and drugs ordered for the patients on their unit, also, nurse with more experience in the unit help to mentor and teach less experienced nurses. All these reasons could demonstrated the highest score of the subscales. This finding is consistent with Dougherty [23]who conducted a study to assess the relationship between emotional Intelligence and nurse-nurse collaboration in the Cardiothoracic, Surgical, Neurosurgical and Coronary ICUs of the Columbia Presbyterian Medical Center, in New York City. The findings of that study revealed that Neurosurgical ICU had significantly higher scores in the nurse-nurse collaboration subscale of professionalism compared with other ICUs in that study.

Regarding nurses opinion about the most frequently missed nursing care, the findings of the current study clears that the most frequently missed nursing care was patient assessment followed by medication administration. The highest percent of nurses reported that they always missed nursing care related to assessing vital signs as ordered, and monitoring intake/output. This may be due to work overload and shortage of nurses, that hinder nurses to provide complete nursing care, in addition to, unexpected rise in patients' volume on the unit and acuity of patients' condition. Added to that nurses did not put patient assessment on the top of their priorities, rather they consider it as a routine task to be performed. This result was incongruent with Attia et al. [15] who reported that the highest area of missed nursing care reported by nurses was related to attendance of interdisciplinary care conference, and disagree also with Abd Elrehem et al. [19] who conducted a study to determine the correlates of missed nursing care in selected medical intensive care units, Egypt. The results of that study illustrates that the highest mean score of the total dimensions of missed nursing care elements reported by the study participants is patient education dimension, while the lowest mean score is monitoring of patients' medical devices and equipment's safety dimension.

The findings of the current study reveals that more than two third of the studied nurses most frequently missed nursing care. This results may be due to the high privacy of data in data collection process which encouraged nurses to report their opinions freely without fear of punishment. This finding disagree with previous research by Attia et al. [15] who reported that the majority of nurses in that study reported a low number of missed nursing cares, and disagree also with Abd Elrehem et al. [19] who reported that the majority of staff nurses never missed the elements of missed nursing care

Regarding nurses opinion about reasons of missed nursing care, the findings of this study shows that the significant reasons of missed nursing care reported by nurses are related to inadequate nursing, number and condition of patient, and unavailability of needed medications. This may be due to that the complexity nature of the intensive care units and the huge variation in the patient acuity level that requires large number of staff and availability of resources and equipment as well as needed medications. This explanation was supported by Nascimento and Erdmanny [3] who mentioned that ICU work is complex and intense and nurses should be prepared to deliver care to patients with important homodynamic alterations at any time. This finding agree with Tubbos-Cooley et al. [24] who conducted a study to describe nurse-reported missed care in neonatal intensive care units at USA and reported that the most common reasons of missed nursing care includes frequent interruption, urgent patient situation, and an unexpected rise in patient volume and/or acuity level. the findings of the present study shows that there was a statistical significant negative correlation between all nurse-nurse collaboration subscales and missed nursing care $(\mathrm{P}$ value $<0.05)$, indicating that nurses who have satisfactory level in nurse-nurse collaboration had low missed nursing care. This finding goes in same direction with Dougherty and Larson[6] who recommended that increasing collaboration among nurses is critical in maintaining a safe and effective therapeutic environment for patients and in reducing medication errors. There was no previous studies examined the relationship between nurse-nurse collaboration and missed nursing care to support our findings. However, there were previous studies that examined the relationship between teamwork and missed nursing care as Attia et al. [15] and Chapman et al. [25] who reported a negative correlation between missed nursing care and teamwork.

Regarding the relationship between missed nursing care and the demographic characteristics of the studied nurses, the findings of the present study revealed significant correlation between total missed nursing care and the demographic characteristics of the study participants related to gender ( $\mathrm{p}$ value $=.045$ ). This may be due to that almost all of the studied subjects were female. This finding disagree with Attia et al. [15] who reported that there were no statistically significant differences between missed nursing care and personal characteristics of nurses. The findings of the current study shows that conflict management subscale has a statistical significant negative correlation with the educational qualification of the studied subjects ( $\mathrm{p}$ value= 
.010). indicating that nurses with higher educational qualification has less skills to manage conflict. This may be due to that nurses with bachelor degree may lack the required skills and experience needed to effectively adapt to the clinical environment compared with diploma nurses or associate nurses who start their practical life early. This variation creates differences in their perceptions about how an issue can be addressed or managed, coupled with the complexity nature of the ICUs, the workload, and the shortage of nursing staff. Or it may be due to that, the over confidence of the bachelor nurses may leads them to undermine the authority of diploma nurses. This finding disagree with Mei-Liang et al. [26] who conducted a study to assess "The Effects of Personality Traits and Conflict Management on Organizational Commitment - A Case Study of Taiwan Financial Services Personnel" and found no relation between conflict management and the education of the studied participants.

\section{Conclusion}

In the light of the current study findings, it was concluded that, the highest percentage of the studied nurses have satisfactory level in all nurse-nurse collaboration subscales. The most frequently missed nursing care as reported by the studied nurses were related to patient assessment and medication administration. The significant reasons of missed nursing care as reported by the studied nurses were inadequate nursing, number and condition of patient, and unavailability of needed medications. There was a statistical significant negative correlation between all nurse-nurse collaboration subscales and missed nursing care.

\section{Recommendations}

Hospital managers and nurse educators should develop educational programs that focus on creating innovative opportunities for nurses to learn about intra-professional collaboration in the practice setting. Nursing educators should develop new recruitment strategies to attract more nurses to the nursing profession. Nursing managers should consider the balanced distribution of nurses to patients in an attempt to prevent or reduce missed nursing care in their units. Other studies should be conducted using direct observation to measure missed nursing care.

\section{Limitation}

The use of self-administered questionnaire to measure missed nursing care. that based on perceptions of nursing staff not a direct observation for nurses performance

\section{Acknowledgements}

The authors would like to thank all ICU nurses who participated in this study and professor Dr,, Labiba Abd ElHamid. Professor of Medical-Surgical, Cairo University for her critical revision of the paper

\section{References}

[1]. Liao, C., Qin, Y., He, Y., \& Guo, Y. The Nurse-Nurse Collaboration Behavior Scale: Development and psychometric testing. International Journal of Nursing Science, (2015). 334-339

[2]. Le Blanc, P. M., Schaufeli, W.B., Salanova, M., B. , M., Llorens, S., \& Nap, R.E. Efficacy beliefs predict collaborative practice among intensive care unit nurses. Journal of Advanced Nursing, 66(3), (2010), 583-594.

[3]. Nascimento, K. c., \& Erdamanny, A. Understanding the dimension of intensive care: Theories. Rev. Latino-Am. Enfermagem; pp. 215-221. (2009)

[4]. Oliveira, A. C., Cardoso, C. S., \& Mascarehas, D. Intensive care Unit professionals" knowledge and behavior related to the adoption of contact precautions. Rev. Latino Am. Enfermagem; pp.625- 631. (2009)

[5]. Rogers, A. E., Dean, G. E., Hwang, W.T., \& Scott, L. D. Role of Registered Nurse in Error Prevention, Discovery and Correction. Quality and Safety in Health Care; 117-121. (2008)

[6]. State of Nebraska Transition Grant. Professional Collaboration for the New Graduate Registered Nurse: Education Module, (2011).

[7]. Dougherty, M, B., \& Larson, E. L. The Nurse-Nurse Collaboration Scale. JONA. 40 (1), (2010) , 17-2

[8]. Zamanzadeh, V., Irajpour, A., Valizadeh, L., \& Shohani, M. The Meaning of Collaboration, from the Perspective of Iranian Nurses: A Qualitative Study. Scientific World Journal, (2014).

[9]. Educator network. What is the difference between Collaboration and Teamwork? Available at https://www.educatornetwork.com/HotTopics/professional learning communities/collaboration vs teamwork. at 14/10/2015, 8 PM.

[10]. Ndundu, L. D. Nurses' Perceptions Of Nurse-Nurse Collaboration In The Intensive Care Units Of A Public Sector Hospital In Johannesburg. Master dissertation, Johannesburg. (2015).

[11]. Kalisch, B., Dana, T., Hyunhwa, L., \& Melanie, S. Does Missed Nursing Care Predict Job Satisfaction? Journal of Healthcare Management; Mar/Apr (2011), 56, 2; ProQuest pg. 117

[12]. Kalisch, B., Landstrom, G., \& Hinshaw, A. Missed nursing care: A concept analysis. Journal of Advanced Nursing, 65(7), (2009), $1509-1517$

[13]. Khalifa, S. M., Dimetry, S. R., Eassa, S., \& ElSalam, A. E. Assessment of medication errors at Zagazig University Hospitals. ZUMJ, 19 (1), (2013). 39-49

[14]. Sabry, N., Farid, S., \& Aziz, E. Role of the pharmacists in identification of medication related problems in the ICU: A preliminary screening study in Egyptian Teaching Hospital. Aust J Basic Appl Sci. (2009); 3:995-1003

[15]. Attia, N. m., Abdeen, M. A., \& El sayed, S. H. Impact of nursing teamwork on missed nursing care in intensive care units at Zagazig University Hospital. Zagazig Nursing Journal. 10 (2), (2014), 201-217

[16]. Yamane, T. Statistics an Introductory Analysis. 2nd Ed. New York Harper and Row (1967).

DOI: 10.9790/1959-0602092835 www.iosrjournals.org


[17]. Kalisch, B. J., \& Williams, R. A. Development and psychometric testing of a tool to measure missed nursing care. J NursAdm; 39 , (2009), 2119.

[18]. Kalisch, B. J., Landstrom, G., \& Williams, R. A. Missed nursing care: Errors of omission. Nurs Outlook; 57, (2010), 3-9.

[19]. Abd Elrehem, M. A. E., Abd El Fatah, M. A., \& Seloma, Y, A. Correlates of Missed Nursing Care in Selected Medical Intensive Care Units, Egypt. Journal of Biology, Agriculture and Healthcare. 4 (26), (2014), 88-105

[20]. Metwally, F. G., \& Hussein, F.M. Collective Self-Esteem, Attitudes Toward Collaboration, and Collaborative Practice Behaviors utilized by Nurses and Physicians . Zagazig Nursing Journal, 12 (1), Jan; (2016). 68-80

[21]. Tuija, Y., Tarja, K., \& Hannele, T. Nurse-nurse collaboration- a survey to the registered nurses in a university hospital. Conference presentation, (2012). available http://www.hphconferences.org/uploads/tx_mhlbihphdb/M1.7_Ylitoermaenen.pd f. at 28/3/2016, $10 \mathrm{AM}$.

[22]. Serrano-Gemes, G., \& Rich-Ruiz, M. Intensity of inter-professional collaboration among intensive care nurses at a tertiary hospital. Enferm Intensiva. 2017 Jan 18. pii: S1130-2399(16)30078-5

[23]. Doughert, M. B. The Relationship between Emotional Intelligence and Nurse-Nurse Collaboration. Doctorate thesis, school of Nursing, Columbia University, (2009).

[24]. Tubbs-Cooley, H. L. , Pickler, R. H., Younger, J .B. \& Mark, B. A . A descriptive study of nurse-reported missed care in neonatal intensive care units. Journal of Advanced Nursing 71(4), (2015), 813-824.

[25]. Chapman, R., Rahman, A. Courtney, M. \& Chalmers, C. Impact of team work on missed care in four Australian hospitals. Journal of Clinical Nursing, 26, (2016), $170-181$

[26]. Mei-Liang, C., Juin-Ming. T., \& Kuang-Jung. C. The Effects of Personality Traits and Conflict Management on Organizational Commitment - A Case Study of Taiwan Financial Services Personnel. The Journal of International Management Studies, 4 (1), February, (2009), 20-29 